\title{
Article \\ Quantitative Estimation of Carbonate Rock Fraction in Karst Regions Using Field Spectra in 2.0-2.5 $\mu \mathrm{m}$
}

\author{
Xiangjian Xie ${ }^{1,2,3}$, Shufang Tian ${ }^{4, *}$, Peijun Du ${ }^{1,2,3, *}$, Wenfeng Zhan ${ }^{1,2,3}$, Alim Samat ${ }^{5}$ \\ and Jike Chen $1,2,3$
}

Received: 22 September 2015; Accepted: 8 January 2016; Published: 15 January 2016

Academic Editors: Eyal Ben-Dor, Magaly Koch and Prasad S. Thenkabail

1 Jiangsu Provincial Key Laboratory of Geographic Information Science and Technology, Nanjing University, Nanjing 210023, China; xiexjrs@gmail.com (X.X.); zhanwenfeng@foxmail.com (W.Z.); jikechen.rs@gmail.com (J.C.)

2 The Key Laboratory for Satellite Mapping Technology and Applications of National Administration of Surveying, Mapping and Geoinformation of China, Nanjing University, Nanjing 210023, China

3 Jiangsu Center for Collaborative Innovation in Geographical Information Resource Development and Application, Nanjing 210023, China

4 School of Earth Sciences and Resources, China University of Geosciences (Beijing), Beijing 100083, China

5 State Key Laboratory of Desert and Oasis Ecology, Xinjiang Institute of Ecology and Geography, Chinese Academy of Sciences, Urumqi 830011, China; alim.smt@gmail.com

* Correspondences: sftian@cugb.edu.cn (S.T.); dupjrs@gmail.com (P.D.); Tel.: +86-136-6109-1988 (S.T.); +86-159-0515-9291 (P.D.)

\begin{abstract}
Considering the important roles of carbonate rock fraction in karst rocky desertification areas and their potential for indicating damage to vegetation, improved knowledge is desired to assess the application of spectroscopy and remote sensing to characterizing and quantifying the biophysical constituents of karst landscapes. In this study, we examined the spectra of major surface constituents in karst areas for direct evidence of absorption features attributable to carbonate rock fraction. Using spectral feature analysis with continuum removal, we observed that there are overlapping spectral absorption in $2.149-2.398 \mu \mathrm{m}$ by soils and non-photosynthetic vegetation. These overlapping features complicated the carbonate absorption feature near $2.340 \mu \mathrm{m}$ in synthetic mixed spectra. To remove the overprint signal, two hyperspectral carbonate rock indices (HCRIs) were developed. Compared to the absorption features including depths, areas, and KRDSIs (karst rocky desertification synthesis indices), linear regression of HCRIs with carbonate rock fraction in linear synthetic mixtures resulted in higher correlations and lower errors. This study demonstrates that spectral variation of the surface constituents spectra in 2.270-2.398 $\mu \mathrm{m}$ region can indicate carbonate rock fraction and be used to quantify them. Still, additional research is needed to advance our understanding of the spectral influences from carbonate petrography relative to carbonate mineralogy, components and physical state of rock surface.
\end{abstract}

Keywords: karst rocky desertification; carbonate rock; land cover fraction estimation; spectroscopy; continuum removal; spectral feature analysis; spectral index

\section{Introduction}

There are tremendous varieties of carbonate rocks existing in a broad range of climatic situations, whose weathering forms diverse types of karst landscapes. Twenty-five percent of the world's population gets its water from karst aquifers. While there may be some debate about the accuracy of these numbers, there is little disagreement on the overall importance of karst environments [1]. The problems in karst management and the sustainability of karst environment are receiving growing 
interest due to the importance of proper exploitation and protection of natural resources [2]. Meanwhile, karst rocky desertification, as one of the most serious problems in land degradation, occurs and develops quickly under the impact of anthropogenic activities. Karst rocky desertification has been characterized as the processes of transformation of vegetation and soil covered karst landscape into exposed basement rock [3-5]. In the desertification areas, the exposure of carbonate rocks is one of the main land surface symptoms [4]. Therefore, the estimation of exposed carbonate rocks is essential for karst ecological conservation and environmental management.

Even though remote sensing provides an important way for understanding karst environments, the mapping of exposed carbonate rocks is still a challenging task because of the highly heterogeneous landscapes in the desertification areas and the limitation in the spatial and spectral resolution of remote sensing images. Many methods have been developed to estimate and map carbonate rocks. For example, exposed carbonate bedrocks can be obtained directly from satellite imagery by visual interpretation [6-8], but it is very time-consuming, labor-intensive and susceptible to interpreter's bias. Recently, an increasing number of digital methods have been developed, such as per-pixel classification [8,9] and subpixel quantitative estimation. As mixed pixels exist abundantly, medium-resolution images, subpixel approaches are widely applied [10,11]; these include spectral mixture analysis (SMA) and spectral index analysis. Linear spectral mixture analysis (LSMA) method has been recently employed to estimate the sub-pixel cover fractions of karst land-surface types [10,11]. For instance, Zhang et al. employed a linear spectral unmixing method to retrieve the abundances of vegetation and exposed rock from Hyperion image [11].

Although SMA is a physical based approach and is able to acquire sub-pixel endmember fractions effectively [12,13], it is extremely difficult to be applied in a large geographic area due to the difficulties in endmember selection. Compared with the SMA method, spectral indices have the advantage of easy implementation and convenience in practical applications without endmember selection. On the one hand, because of the nearly inverse correlation between carbonate rocks and green vegetation or bare soil cover in karst areas, one potential approach is the utilization of spectral indices on vegetation and bare soils. Therefore, exposed carbonate rock fraction is usually estimated based on: (1) complement of vegetation and bare soil fraction; or (2) regression models with vegetation and bare soil indices $[14,15]$. The other common strategy is to develop directly spectral indices for exposed carbonate rocks. For instance, Xia et al. defined a geometrical rock desertification index (GRI) with IKONOS image [16]. Tong used the ratio of band 5 and band 4 to enhance exposed carbonate rocks in TM imagery [17]. Xie et al. derived two carbonate rock indices from the Blue and NIR bands of Landsat-8 OLI imagery [18].

These multispectral index approaches reveal the potential for estimation of land degradation in karst areas using satellite images. Since spectrometry provides near-contiguous and narrowband spectral analysis of the land surface, which has been proven useful for studying a wide variety of biophysical and geological processes [19], and which has been applied to derive spectral indices for estimating and mapping karst rocky desertification. For example, Yue et al. proposed karst rocky desertification synthesis indices (KRDSIs) based on field spectral reflectance of non-photosynthetic vegetation (NPV), soils and exposed rocks, KRDSIs were then applied in Hyperion imagery to estimate the fractional cover of exposed rocks [20,21]. Although many scholars have had in-depth discussions of visible and near-infrared spectra of carbonate mineral and rock [22-27], improved knowledge is desired to assess the application of spectroscopy to characterizing and quantifying exposed carbonate rocks. The unaddressed problems include: what are the absorption features in the reflectance spectra of major surface constituents in karst areas? and what about mixed spectra of the constituents? Additional fundamental information about the impact of different biophysical constituents on mixed spectra is needed to assess the contribution of exposed carbonate rocks; Which spectral bands or features are more sensitive to carbonate rock fraction in mixed scenes, and how can they be introduced into the estimation model? 
Our objectives in this paper are: (1) to add to the understanding of the reflectance spectra of major surface constituents in karst areas; (2) to examine the mixed spectra of the constituents in the 2.0-2.5 $\mu \mathrm{m}$ region for direct evidence of absorption features attributable to exposed carbonate rock fractions; and (3) to explore more robust absorption features for fractional estimation. To accomplish these objectives, firstly, we present field spectra of surface constituents in karst areas, including exposed carbonate rocks, green vegetation, NPV and soils in Southwestern China. Then, several synthetic mixed spectra data sets are generated based on a linear spectral mixture assumption. Utilizing linear continuum removal, we apply spectral feature analysis (SFA [28]) to examine absorption features in the synthetic mixed spectra and contrast them with the ones in spectra of the pure constituents. We subsequently modify the parameters in KRDSIs and develop two hyperspectral carbonate rock indices (HCRIs) for characterizing exposed carbonate rocks. Finally, the relationships between HCRIs and exposed carbonate rock fractions are tested by comparing with KRDSIs and SFA absorption feature parameters (e.g., center, depth, and area).

\section{Materials and Methods}

\subsection{Surface Constituents in Karst Rocky Desertification Areas}

In many karst areas, there are extensive areas of bare carbonate rocks where intervening fissures and underlying caves frequently [29]. For example, the bare appearance of many karst landscapes in sourthwestern China has been regarded as a result of the human-induced deforestation, early agriculture and subsequent soil erosion [4]. In these karst rocky desertification areas, exposed carbonate bedrock is one of the major surface constituents, along with soil and green vegetation. Furthermore, there is also large crop residue cover on the farmland in the harvest seasons.

\subsection{Spectral Measurements of the Surface Constituents}

These typical surface constituents (including exposed carbonate bedrocks, soils, green vegetation and NPV) were collected and measured in a karst peak-cluster depression region in northeastern Jianshui County, Yunnan Province, China, which is located on $23^{\circ} 31^{\prime} 33.49^{\prime \prime}-23^{\circ} 48^{\prime} 39.12^{\prime \prime} \mathrm{N}$ and $102^{\circ} 40^{\prime} 24.87^{\prime \prime}-103^{\circ} 7^{\prime} 54.70^{\prime \prime} \mathrm{E}$. The measurements of carbonate rocks, plant leaves or canopies, grasses, corn stalks and soils were acquired using a portable spectrometer (Analytical Spectral Devices (ASD) Inc., FieldSpec 4, Boulder, CO, USA), fitted with a 25 degree field-of-view bare fiber-optic. The ASD field spectroradiometer works with a bandwidth of $1.4 \mathrm{~nm}$ in the spectral range $0.35-1.0 \mu \mathrm{m}$, and a bandwidth of $2 \mathrm{~nm}$ in the range 1.0-2.5 $\mu \mathrm{m}$. The magnitude of measured spectral radiance depends on the amount of incoming solar radiation (spectral irradiance) reaching the target, and this can vary significantly according to date and time of day, atmospheric conditions, local orientation of the surface, and intervening features which may further alter or attenuate incoming radiation (e.g., shadowing). Therefore, radiance measurements were converted to target reflectance using a calibrated white spectralon panel. The objective of this procedure is to minimize errors due to variations in atmospheric conditions and sun inclination.

During field reflectance spectra measurement, the bidirectional effects of the target reflectance were accounted for by carrying out measurements over very short time intervals and in a vertical position. Because the amounts of samples varied, the fiber optic head was adjusted to ensure that the field of view included only the sample material being measured. In addition, the instrument was programmed to record per second averages of reflectance (thus, each recorded spectrum was an average of 10 individual measurements). Measurements were taken between 20 March and 22 March 2015, with typical "dry-season" conditions (i.e., less cloud). Figure 1 show examples of field reflectance spectra measured from different surface constituents in the karst desertification area in northeastern Jianshui County. A total of 72 reflectance spectra from carbonate bedrocks, 53 from green vegetation, 10 from NPV and 30 from soils were collected. All the spectrum samples were used in our spectroscopy experiment. 

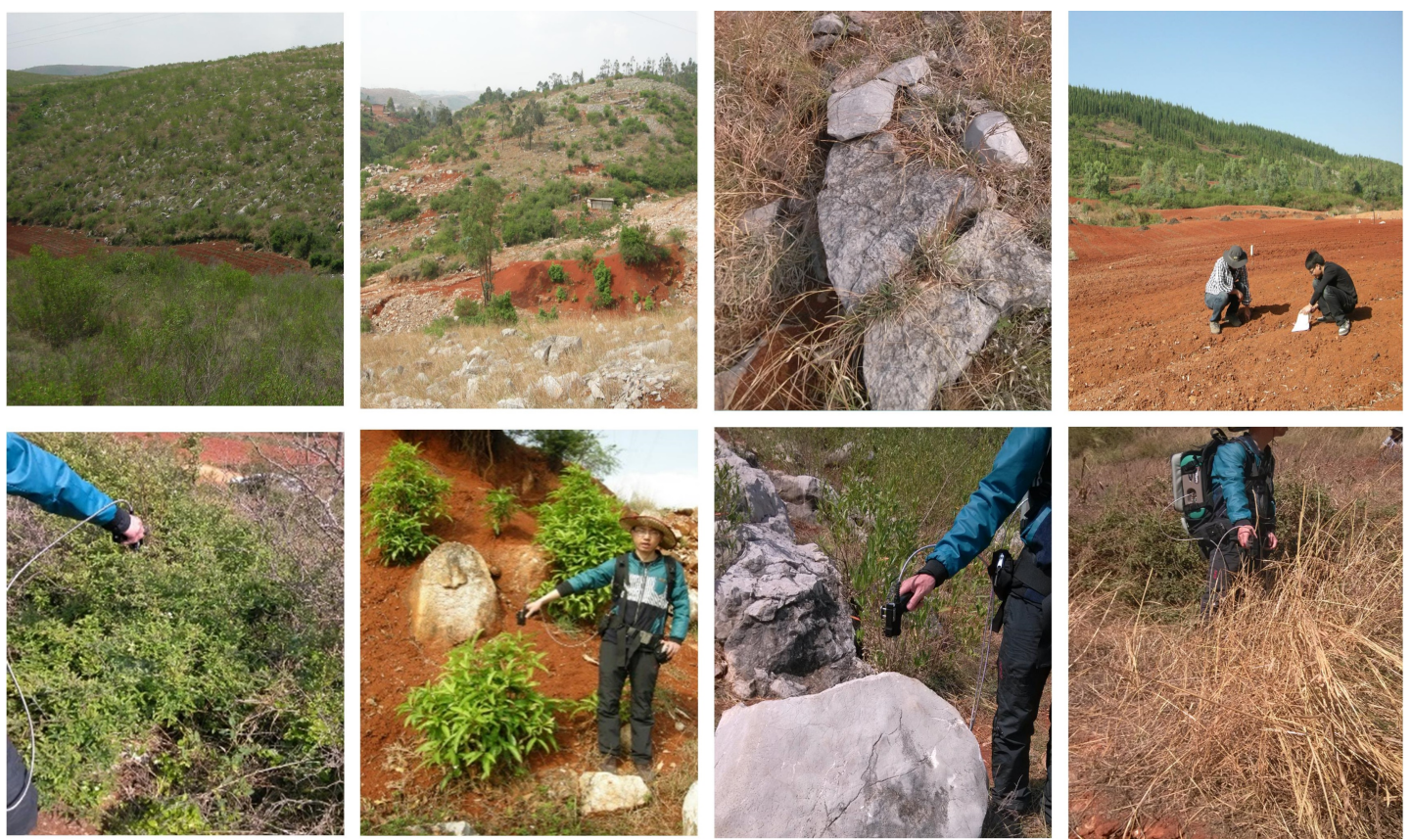

Figure 1. The pictures depict examples of field reflectance spectra measured from different surface constituents in Eastern Yunnan, China.

\subsection{Spectral Processing}

All spectra were processed and analyzed using several spectral processing routines. The routines achieve some basic spectral preprocessing functions, including correcting detector offsets, averaging and absolute reflectance conversion [30]. To analyze spectral features, we also added the functions of continuum removal and spectral feature analysis as described in [28,30], in addition to calculation of KRDSIs [20] and the proposed index in this study.

There are three detectors covering the wavelength ranges $0.350-1.000,1.001-1.800$, and 1.801-2.500 $\mu \mathrm{m}$. For the offsets between detectors arising from the spectrometer design, we applied simple multiplicative factors to correct them [30]. In addition, the absolute reflectance $(R)$ as a function of wavelength $(\lambda)$ was obtained by multiplying the reflectance measurement made relative to Spectralon $\left(R_{r e f}\right)$ by the reflectance of Spectralon:

$$
R(\lambda)=R_{\text {ref }} \times R_{\text {Spectralon }}(\lambda)
$$

Figure 2 illustrates the preprocessing for field measurements of exposed carbonate rock, including the averaged, absolute reflectance spectrum with offsets corrected, along with one of the measured spectra for comparison. Because the second detector has been considered to be more stable at the end points of its wavelength coverage than the other detectors, the first and third detectors are adjusted to be consistent with the second one [30]. Furthermore, the wavelengths removed correspond to strong atmospheric water vapor absorption bands between 1.356 and $1.417 \mu \mathrm{m}, 1.820$ and $1.932 \mu \mathrm{m}$, and above $2.45 \mu \mathrm{m}$. 


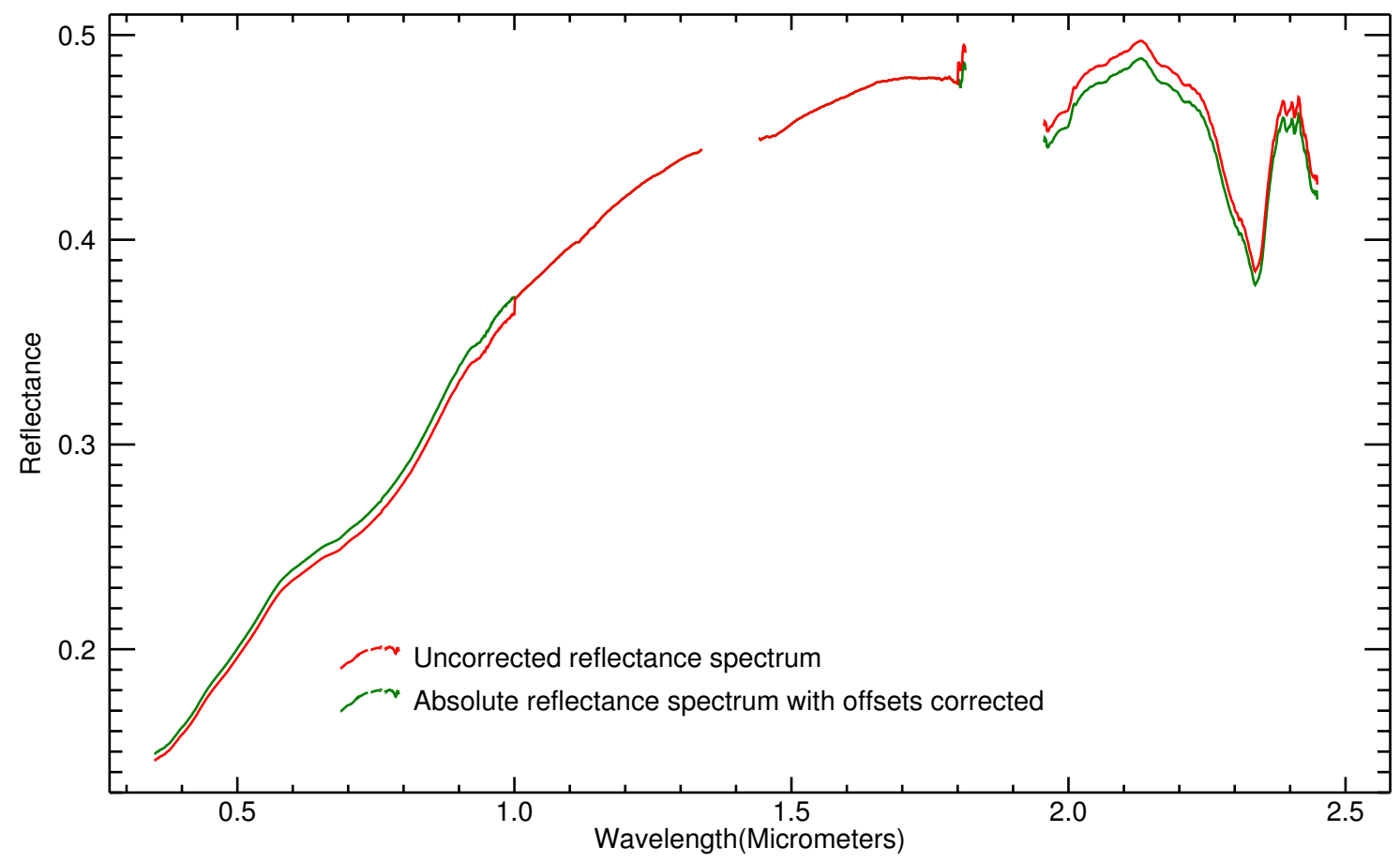

Figure 2. Comparison of relative reflectance with uncorrected offsets and averaged, absolute reflectance spectrum with offsets corrected.

\subsection{Synthetic Mixed Spectra}

Compared to classification, a more suitable way of extracting information from mixed scenes is to try to estimate how each pixel's area is divided up among different surface constituents. This approach has been termed mixture modelling. Among a number of estimators, the linear mixture model is perhaps the most preferable estimator, which has been most commonly used or implicitly assumed in previous studies of mixing in remote sensing [31]. Therefore, three synthetic mixed spectra data sets were created based on the basic physical assumptions underlying the linear mixture model: there is no significant amount of multiple scattering between different karst surface constituents; each photon that reaches the sensor interacts with only one constituent [31]; and the mixture of surface constituents is areal. Our task is to characterize the absorption features of major surface constituents in mixed spectra in the short-wave infrared (SWIR) region, and determine which spectral bands or features derived from mixed spectra can be applied to estimate the carbonate rock fraction.

Four surface cover fractions were created $\left(x_{1}, x_{2}, x_{3}, x_{4}\right)$. In order to ensure a high probability of a pure sample for any of the four surface cover constituents, while evenly distributing the chance for any one cover constituent to be either high or low in any given sample, they were calculated by firstly generating four random variables, which were between 0 and 1 . All of the four variables were divided by the sum of them, it was determined by the condition that the fraction values should sum to one. One to four of the values of each variable were then assigned to the fractions of exposed carbonate rock, green vegetation, soil and NPV. Once the surface cover fractions were determined, synthetic reflectance spectrum was calculated by simple linear mixture. Three synthetic data sets were generated to analyze different features of surface cover mixed spectra along with varied carbonate rock fractions (see Table 1). At first, we chose the four representative surface cover reflectance spectra as endmembers (one for each constituent) to generate one data set of synthetic mixed spectra (data set ${ }_{1}$ ). Then, the second data set was generated from mixtures of a representative reflectance spectrum of carbonate rock and the other three randomly selected reflectance spectra of each surface cover (data set ${ }_{2}$ ). At last, those selected randomly from the reflectance spectra of each surface cover were chosen as endmembers 
to create the third data set of verification samples (data set 3 ). Since any single sample is dominated by one type of carbonate rocks, green vegetation, soil or NPV, these mixtures can reflect the circumstances found in a number of karst rocky desertification areas.

Table 1. Description of synthetic spectra with linear mixture model.

\begin{tabular}{cccccc}
\hline \multirow{2}{*}{ Synthetic Spectra } & \multicolumn{4}{c}{ Endmembers } & \multirow{2}{*}{ Mixture Model } \\
\cline { 2 - 4 } & Rock & Soil & Vegetation & NPV & \\
\hline Data set $_{1}$ & Fixed $^{1}$ & Fixed & Fixed & Fixed & Linear \\
Data set $_{2}$ & Fixed & Random & Random & Random & Linear \\
Data set & Random $_{3}$ & Random & Random & Random & Linear \\
\hline
\end{tabular}

\footnotetext{
${ }^{1}$ A representative reflectance spectrum was chosen as a fixed endmember of the mixture;

2 The reflectance spectrum selected randomly from sample spectra was chosen as an endmember of the mixture.
}

\subsection{Spectral Analysis}

\subsubsection{Spectral Feature Analysis}

There are various techniques of processing reflectance spectra to obtain constitutional information of mixtures. For example, continuum removal is used to enhance absorption features in reflectance spectra [32-37], which has been applied to map the distribution of minerals and vegetation or estimate geochemistry and foliar biochemical content or concentrations [30,38-41]. The continuum removal (as displayed in Figure 3) can be performed as follows [32]:

$$
R_{C}(\lambda)=R(\lambda) / R_{L}(\lambda)
$$

where $R_{C}$ is the continuum removed spectrum, $R$ is the original observed spectrum, and $R_{L}$ is the corresponding values of the continuum line for all the channels in the wavelength region between the endpoints of the absorption feature.

The continuum-removed feature was further analyzed to compute parameters that describe the absorption feature, such as the central wavelength position, feature depth, area of the absorption and absorption asymmetry [23,42]. Figure 3 illustrates the spectra after continuum removal where the absorption feature is enhanced. The absorption-band position, $\lambda_{c}$, is defined as the wavelength with the minimum spectral response within the wavelength range of the absorption feature under consideration. The relative depth, $D$, of the absorption feature is defined as the difference between the continuum line and the minimum value in the continuum-removed spectra:

$$
D=1.0-\min \left(R_{C}\right)
$$

The area of the absorption is defined as the sum of individual areas between the continuum line and channels in the continuum-removed feature, which is mathematically described as

$$
A=\sum_{i=1}^{n}\left(1-R_{C}(i)\right),
$$

where $n$ is the number of bands from the starting point to the end point. Given that calculation of areas leads to erroneous estimates in coarse sampled spectral data sets, the asymmetry factor perhaps is a good approximation [40]. The asymmetry factor, $S$, of the absorption feature is defined as

$$
S=A_{\text {left }} / A_{\text {right }}
$$

where $A_{\text {left }}$ is the area of the absorption from the starting point to the maximum absorption point and the $A_{\text {left }}$ is the area of the absorption from maximum absorption point to the end point of the absorption. 


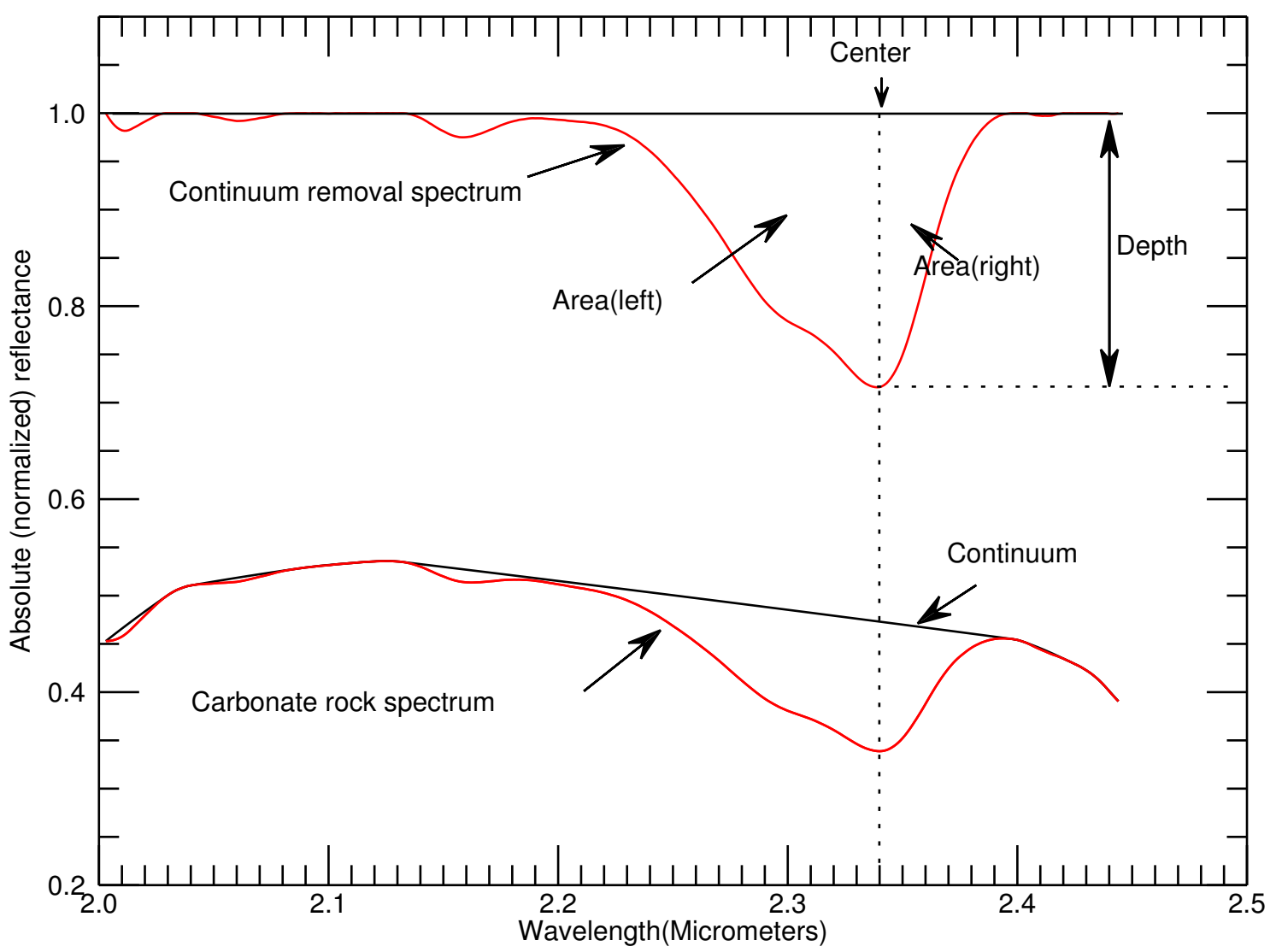

Figure 3. Definition of the continuum and continuum removal of absorption features [32-37]. The carbonate rock spectrum is the average of measured spectra.

\subsubsection{Spectral Indices}

In addition to spectral feature analysis, spectral indices have been applied to analyse surface cover fractions or estimate geochemistry and foliar biochemical content [20,43-46]. Because the wavelength positions of spectral absorption center and shoulders are the three most important parameters of spectral absorption features, Yue et al. developed four indices named KRDSIs based on them for the estimation of surface constituents [20], which were defined as

$$
\begin{gathered}
\operatorname{KRDSI}_{1}=\left(R\left(\lambda_{a}\right)+R\left(\lambda_{b}\right)\right) / 2 R\left(\lambda_{c}\right) ; \\
\operatorname{KRDSI}_{2}=\left(R\left(\lambda_{a}\right)+R\left(\lambda_{b}\right)\right)-2 R\left(\lambda_{c}\right) ; \\
\operatorname{KRDSI}_{3}=R_{L}\left(\lambda_{c}\right)-R\left(\lambda_{c}\right) ; \\
\mathrm{KRDSI}_{4}=I_{L}-I,
\end{gathered}
$$

where $\lambda_{a}$ and $\lambda_{b}$ are the wavelengths of two shoulders in spectra of non-vegetation, $I_{L}$ is the integral of interpolated reflectance values between $\lambda_{a}$ and $\lambda_{b}$, and $I$ is the integral of observed spectral curve between wavelengths $\lambda_{a}$ and $\lambda_{b}$. In terms of the estimation of exposed bedrock fractions, Yue $e t a l$. defined that $\lambda_{a}=2.200 \mu \mathrm{m}, \lambda_{b}=2.380 \mu \mathrm{m}$ and $\lambda_{c}=2.350 \mu \mathrm{m}$ in [20].

After the analysis of reflectance spectra of major surface constituents in the desertification areas and artificial mixed spectra, we found that, to a great extent, the absorption features in 2.149-2.398 $\mu \mathrm{m}$ of mixed spectra depended not only on carbonate rocks but also on the other surface constituents (including green vegetation, soils and NPV) in the surface mixtures. In particular, there is a overlapping absorption near $2.208 \mu \mathrm{m}$ caused by soils (see Table 2 and Figure 4), while the other three constituents have similar sightly absorption in the reflectance spectra in the $2.270-2.398 \mu \mathrm{m}$ region, with the exception of carbonate rocks. The reflectance spectra of the other surface constituents are of different 
shapes in the 2.149-2.398 $\mu \mathrm{m}$ region, in contrast, the spectra of them have slowly changing and similar shapes in the 2.340-2.398 $\mu \mathrm{m}$ region (see Figure 4). Therefore, we adjusted the parameters $\lambda_{a}, \lambda_{b}$ and $\lambda_{c}$ in KRDSIs and derived two hyperspectral carbonate rock indices (HCRIs) from them, with the purpose of removing overprint of soil and vegetation signal in the $2.149-2.398 \mu \mathrm{m}$ and retaining the spectral absorption feature of carbonate rocks at $2.30-2.35 \mu \mathrm{m}$. The proposed indices are defined as

$$
H C R I_{1}=R\left(\lambda_{2}\right)-R\left(\lambda_{0}\right)
$$

and

$$
H C R I_{2}=R_{L}\left(\lambda_{0}\right)-R\left(\lambda_{0}\right),
$$

where $\lambda_{2}$ is defined as right endpoint in absorption reflectance spectra of carbonate rocks near $2.340 \mu \mathrm{m}$, according to feature parameters for absorption of carbonate rocks showed in Table $3, \lambda_{2}=2.398 \mu \mathrm{m}$; the carbonate absorption-band position, $\lambda_{0}$, is defined as the band having the minimum reflectance value over the wavelength range of 2.3-2.35 $\mu \mathrm{m}$ [23]. It is designed to remove the influence of varying absorption center wavelength from $2.30 \mu \mathrm{m}$ to $2.35 \mu \mathrm{m}$ of limestone and dolomite. $R_{L}\left(\lambda_{0}\right)$ is the corresponding value of the continuum line in the wavelength region between $\lambda_{1}=2.270 \mu \mathrm{m}$ and $\lambda_{2}=2.398 \mu \mathrm{m}$.

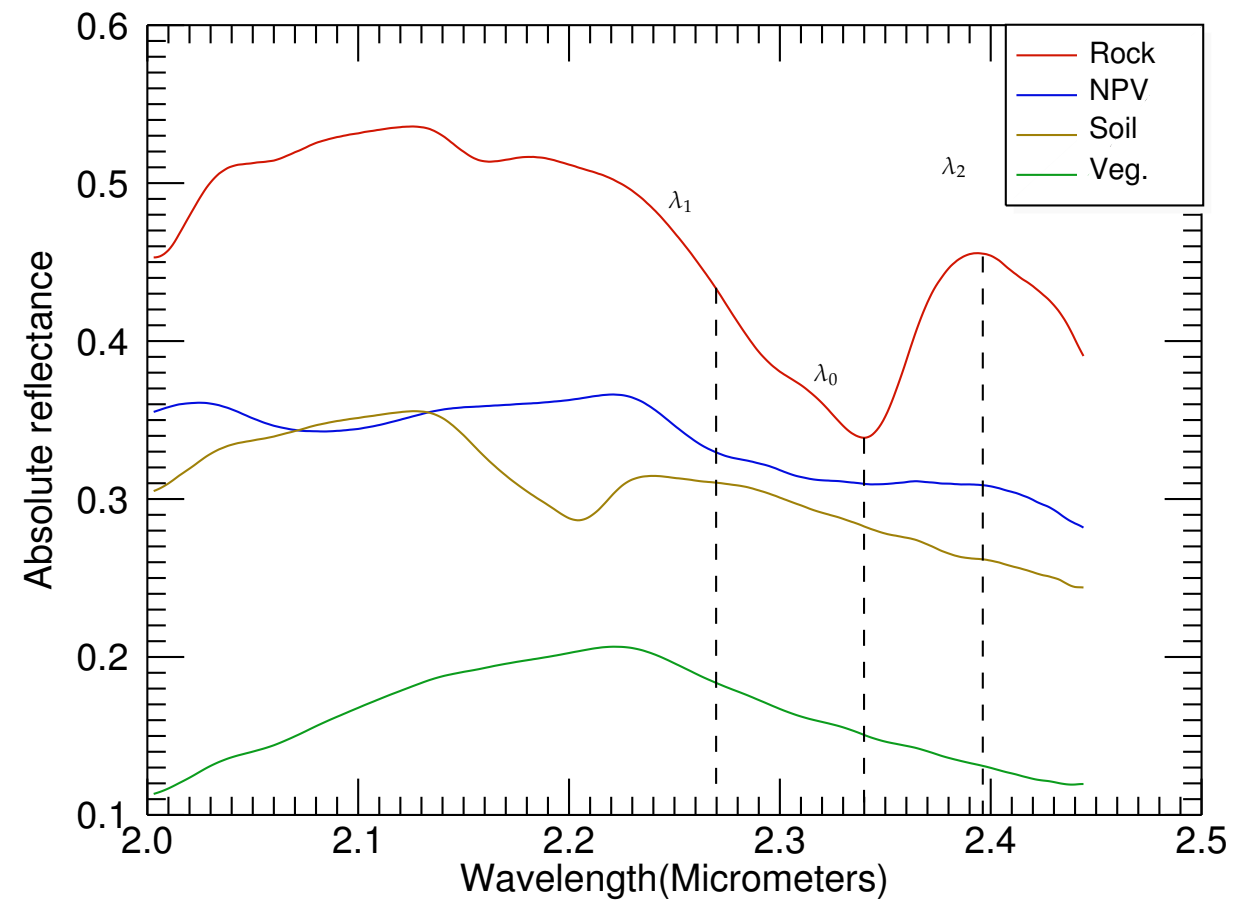

Figure 4. Reflectance spectra of surface constituents in karst rocky desertification areas and the parameters of HCRIs: $\lambda_{0}, \lambda_{1}$ and $\lambda_{2}$.

Table 2. Feature parameters for absorption of the four surface constituents in 2.0-2.5 $\mu \mathrm{m}$.

\begin{tabular}{ccccccccccc}
\hline \multirow{2}{*}{ Surface Constituent } & \multicolumn{2}{c}{ Left Endpoint $(\mu \mathbf{m})$} & \multicolumn{2}{c}{ Right Endpoint $(\mu \mathbf{m})$} & \multicolumn{2}{c}{ Center $(\mu \mathbf{m})$} & \multicolumn{2}{c}{ Depth } & \multicolumn{2}{c}{ Area $(\mathbf{n m})$} \\
\cline { 2 - 10 } & Avg. & std. dev. & Avg. & std. dev. & Avg. & std. dev. & Avg. & std. dev. & Avg. & std. dev. \\
\hline Carbonate rock & 2.1494 & 0.0359 & 2.3976 & 0.0012 & 2.3397 & 0.0008 & 0.3057 & 0.0718 & 26.6160 & 6.9708 \\
Soil & 2.1333 & 0.0034 & 2.3043 & 0.0376 & 2.2030 & 0.0015 & 0.1586 & 0.0771 & 9.9981 & 5.2913 \\
Green vegetation & 2.2382 & 0.0097 & 2.4431 & 0.0033 & 2.3523 & 0.0406 & 0.0851 & 0.0292 & 9.0048 & 4.1032 \\
NPV & 2.1478 & 0.1098 & 2.3350 & 0.1046 & 2.2196 & 0.1229 & 0.0837 & 0.0157 & 6.1711 & 1.4092 \\
\hline
\end{tabular}


Table 3. Feature parameters for absorption of carbonate rocks near $2.340 \mu \mathrm{m}$.

\begin{tabular}{ccccccc}
\hline $\begin{array}{c}\text { Sample } \\
\text { Identifiers }\end{array}$ & $\begin{array}{c}\text { Left Endpoint } \\
(\boldsymbol{\mu} \mathbf{m})\end{array}$ & $\begin{array}{c}\text { Right Endpoint } \\
(\mu \mathbf{m})\end{array}$ & Center $(\mu \mathbf{m})$ & Depth & Area (nm) & Asymmetry \\
\hline$\# 1$ & 2.132 & 2.398 & 2.339 & 0.2316 & 20.1509 & 3.2252 \\
$\# 2$ & 2.128 & 2.394 & 2.338 & 0.3173 & 26.8978 & 2.7564 \\
$\# 3$ & 2.128 & 2.398 & 2.340 & 0.3924 & 35.3544 & 2.9720 \\
$\# 4$ & 2.216 & 2.398 & 2.339 & 0.3246 & 27.4590 & 2.6701 \\
$\# 5$ & 2.128 & 2.398 & 2.340 & 0.4316 & 38.6760 & 2.9305 \\
$\# 6$ & 2.133 & 2.398 & 2.341 & 0.2398 & 20.1119 & 3.2333 \\
$\# 7$ & 2.219 & 2.398 & 2.340 & 0.2512 & 20.3219 & 2.9047 \\
$\# 8$ & 2.128 & 2.398 & 2.340 & 0.4055 & 36.4791 & 2.9427 \\
$\# 9$ & 2.131 & 2.398 & 2.340 & 0.2816 & 24.5707 & 3.0008 \\
$\# 10$ & 2.131 & 2.398 & 2.339 & 0.2331 & 21.0690 & 3.1257 \\
$\# 11$ & 2.188 & 2.397 & 2.340 & 0.2411 & 19.4705 & 3.0124 \\
$\# 12$ & 2.131 & 2.398 & 2.340 & 0.3186 & 28.8311 & 3.1955 \\
\hline
\end{tabular}

\subsection{Linear Regression with Carbonate Rock Fraction}

Linear regression was used to test if the above mentioned absorption features were linearly related to carbonate rock fraction in karst surface mixtures. Firstly, the automated spectral feature analysis and related indices were applied to the synthetic mixed spectra. Then, we related SFA parameters, KRDSIs and HCRIs, separately, with the exposed carbonate rock fraction. Regressions were calculated using SFA parameters, HCRIs and KRDSIs derived from the fixed parameters in reference to [20]. At last, three parameters, including the Pearson product-moment correlation coefficient $(r)$, the root-mean square error (RMSE) and the Chi-Square $\left(\chi^{2}\right)$ between actual and predicted values, were used to evaluate the regression results.

\section{Experimental Results}

\subsection{Spectra of Surface Constituents in Karst Rocky Desertification Areas in SWIR 2.0-2.5 $\mu \mathrm{m}$}

Preprocessed reflectance spectra of the surface constituents are depicted in Figure 5, Figure 5a shows the reflectance of exposed carbonate rocks in SWIR 2.0-2.5 $\mu \mathrm{m}$, From 2.131 to $2.389 \mu \mathrm{m}$, the carbonate bedrocks exhibit a stronger absorption feature centered near $2.340 \mu \mathrm{m}$, arising from vibrational processes of the carbonate ions $\left(\mathrm{CO}_{3}^{2-}\right)$ [25]. This feature shifts slightly in the wavelength position, and the absorption has asymmetrical shape with various absorption area and depth (Table 3 ).

Reflectance spectra of soils are shown in Figure $5 \mathrm{~b}$. All spectra of soils exhibit similar absorption about a central wavelength near $2.203 \mu \mathrm{m}$, which is caused by hydroxyl $(-\mathrm{OH})$ stretch vibration in the soils $[47,48]$. Because soil in carbonated areas is typically rich in clay, which is formed in dissolution of $\mathrm{CaCO}_{3}$ by rain water. They have no absorption feature in $2.340 \mu \mathrm{m}$. Figure $5 \mathrm{c}$ depicts example reflectance spectra for green vegetation. There is no obvious absorption in SWIR 2.0-2.5 $\mu \mathrm{m}$, while it has a weak peak in reflectance spectra near $2.220 \mu \mathrm{m}$. As illustrated in Figure 5d, the reflectance spectra of non-photosynthetic vegetation have different shapes. In 2.0-2.5 $\mu \mathrm{m}$ region, NPV exhibits two small but broad absorption features centered near $2.086 \mu \mathrm{m}$ and $2.3 \mu \mathrm{m}$, and shows a peak in reflectance near $2.225 \mu \mathrm{m}$. 

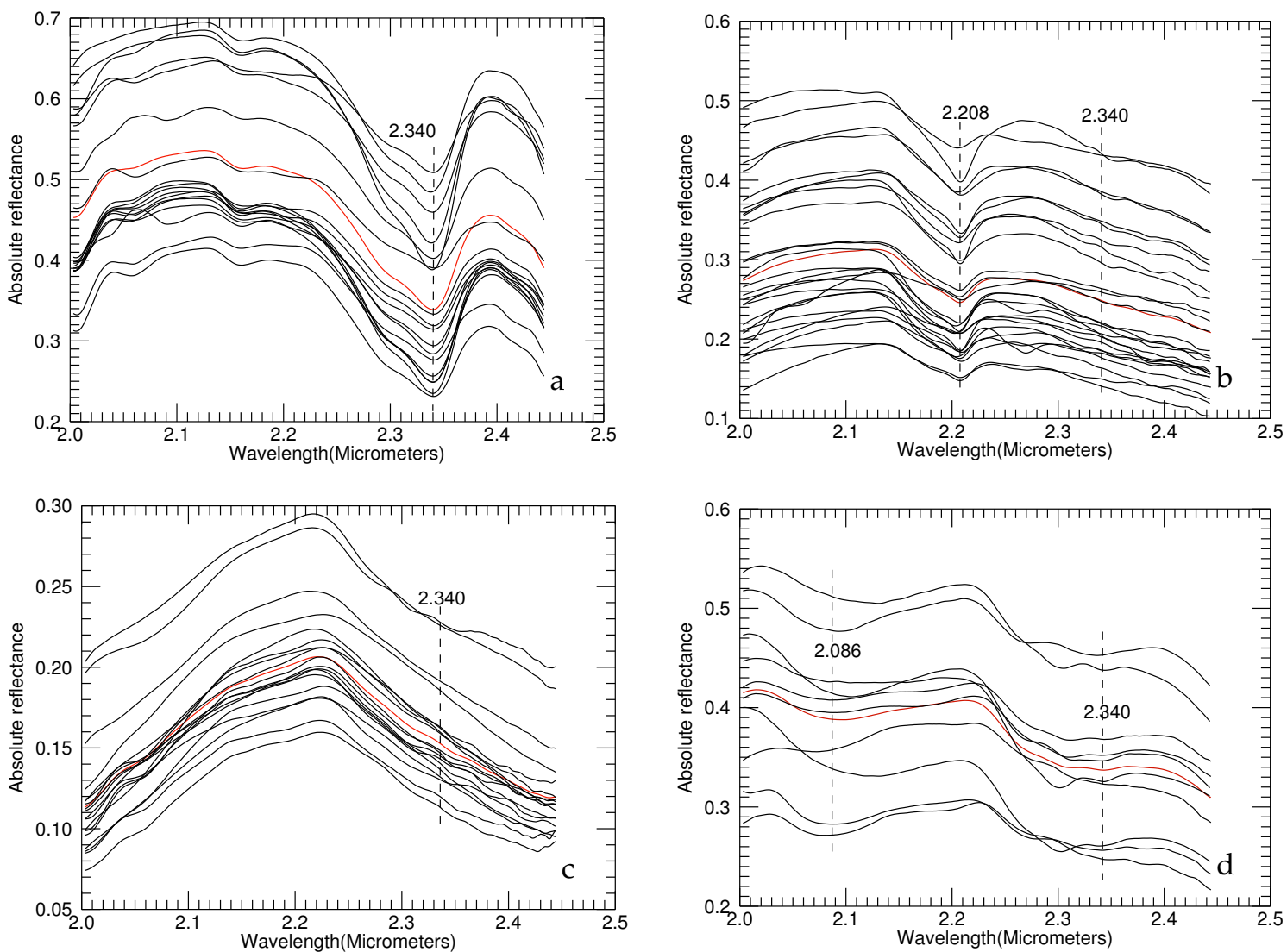

Figure 5. Reflectance spectra of the surface constituents in 2.0-2.5 $\mu \mathrm{m}$ : (a) exposed carbonate rocks; (b) soils; (c) green vegetation; and (d) NPV. The mean reflectance spectra are colored red.

\subsection{Continuum-Removed Spectra}

Continuum-removed spectra of the $2.340 \mu \mathrm{m}$ feature in selected carbonate rock, soil, green vegetation and NPV samples are depicted in Figure 6a. The spectra have been plotted in one figure so the differences in feature center and spectral shape can be more clearly seen. Among the four surface constituents, carbonate rock has the strongest absorption features near $2.340 \mu \mathrm{m}$, with 0.4055 of depth and $36.4791 \mathrm{~nm}$ of absorption area (Table 3), and these features in green vegetation and NPV are weak. Soil has a feature at shorter wavelength position near $2.203 \mu \mathrm{m}$. Table 2 shows feature parameters for absorption of the surface constituents near $2.340 \mu \mathrm{m}$, where carbonate rocks have the largest average value 0.3057 of Depth and $26.6160 \mathrm{~nm}$ of absorption area, and the large standard deviation value 0.0718 and 6.9708 . 

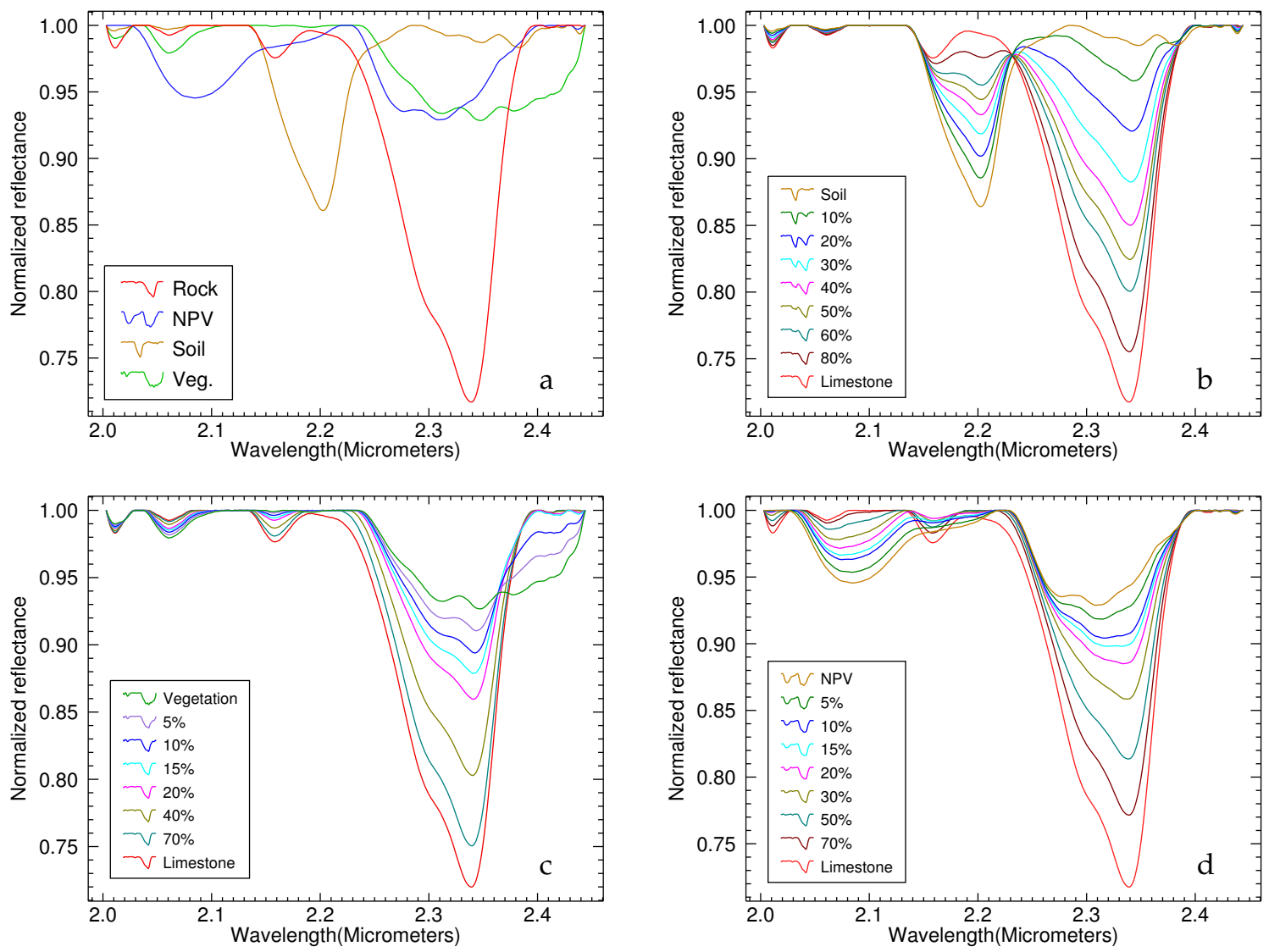

Figure 6. Continuum-removed spectra for absorption features in the spectra of: (a) selected surface constituents; (b) mixtures of the soil and carbonate rock; (c) mixtures of the green vegetation and carbonate rock; (d) mixtures of the NPV and carbonate rock.

\subsection{Synthetic Mixed Spectra}

Figure $6 \mathrm{~b}-\mathrm{d}$ depicts continuum-removed spectra of synthetic mixtures with different carbonate rock fractions. Pair-wise mixtures of carbonate rocks and the other three constituents are displayed respectively, so that different contributions to mixed spectra absorption in 2.0-2.5 $\mu \mathrm{m}$ region from the other three constituents' fractions can be clearly seen. Figure $6 \mathrm{~b}$ describes two significant absorption in mixed spectra of carbonate rock and soil, and the position of strongest absorption jumps from $2.203 \mu \mathrm{m}$ to $2.340 \mu \mathrm{m}$ when the fraction of carbonate rock increases to a threshold (about 25\%) Comparatively, the absorption center shifts slightly near $2.340 \mu \mathrm{m}$ in mixed spectra of green vegetation and carbonate rocks, and the absorption width is becoming broader obviously as carbonate rock fraction decline from $10 \%$ (see Figure $6 \mathrm{c}$ ). As illustrated in Figure $6 \mathrm{~d}$, there is a double floating absorption in mixed spectra of carbonate rock and NPV, the position of the strongest absorption generally shifts from a longer wavelength for larger carbonate rock fractions to shorter wavelength in the larger NPV fractions. Therefore, the relationship of the occurrence and spectral parameters of absorption features typical of certain cover is not linear to the different contents of the mixture [49].

\subsection{Relativity between the Surface CarbonateRock Fractions and $2.340 \mu \mathrm{m}$ Absorption Features}

Linear regression results for the carbonate rock fractions related to the $2.340 \mu \mathrm{m}$ absorption features, including centers, depths, areas, asymmetry, KRDSIs and HCRIs, are described in Table 4. The table shows expected results. Synthetic spectra with representative spectra perform better than synthetic spectra from randomly chosen spectra in a sample. For the data set ${ }_{2}$, with fixed parameters $\lambda_{a}=2.2 \mu \mathrm{m}, \lambda_{b}=2.35 \mu \mathrm{m}$ and $\lambda_{c}=2.38 \mu \mathrm{m}, \mathrm{KRDSI}_{3}$ has higher $r(0.9853)$ and lower RMSE (0.0492) 
and Chi-Square (4.5504) value than other KRDSIs. Comparatively, the HCRIs with adjusted parameters $\lambda_{1}=2.270 \mu \mathrm{m}, \lambda_{2}=2.398 \mu \mathrm{m}$ and the adaptive $\lambda_{0}$ have higher $r$ and lower RMSE and Chi-Square value than the KRDSIs, the highest Pearson correlation coefficient and lowest RMSE and Chi-Square values are obtained for the feature $\mathrm{HCRI}_{2}\left(r=0.9988\right.$, RMSE $=0.0144$ and $\left.\chi^{2}=0.4126\right)$. In the experiment for data set s $_{3} \mathrm{KRDSI}_{4}$ has the higher $r$ and lower RMSE than other KRDSIs with fixed absorption parameters. In contrast, the feature HCRIs with adjusted parameters have better performance than KRDSIs and SFA features. The highest $r$ and lowest RMSE and Chi-Square values are obtained for the feature $\mathrm{HCRI}_{2}\left(r=0.7976, \mathrm{RMSE}=0.1740\right.$ and $\left.\chi^{2}=54.4868\right)$. Meanwhile, SFA feature centers and asymmetry have the highest RMSE and Chi-Square and lowest $r$ both for data set 2 and data set 3 .

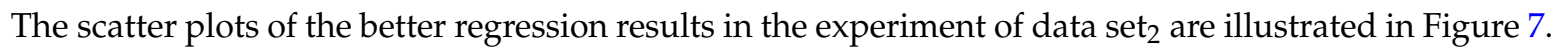
Relative to the carbonate rock fractions, the feature HCRIs have very good fitting results for different carbonate rock fractions, $r$ of 0.9943 and 0.9988 , respectively. With $\lambda_{a}=2.2 \mu \mathrm{m}, \lambda_{b}=2.35 \mu \mathrm{m}$ and $\lambda_{c}=2.38 \mu \mathrm{m}, \mathrm{KRDSI}_{2}, \mathrm{KRDSI}_{3}$ and feature area have lower $r$ and more discrete distribution of points, especially at the low carbonate rock fractions level.

Table 4. Linear regression results for $2.340 \mu \mathrm{m}$ absorption features and carbonate rock fraction in two synthetic surface mixtures.

\begin{tabular}{lcccccc}
\hline \multirow{2}{*}{ Feature } & \multicolumn{3}{c}{ Data set $_{2}$} & \multicolumn{3}{c}{ Data set $_{3}$} \\
\cline { 2 - 7 } & $r$ & RMSE & $\chi^{2}$ & $r$ & RMSE & $\chi^{2}$ \\
\hline KRDSI $_{1}$ & 0.9695 & 0.0706 & 9.6562 & 0.4830 & 0.2524 & 286.5752 \\
KRDSI $_{2}$ & 0.9839 & 0.0515 & 4.9257 & 0.5924 & 0.2322 & 242.6249 \\
KRDSI $_{3}$ & 0.9853 & 0.0492 & 4.5504 & 0.6379 & 0.2219 & 221.6684 \\
KRDSI $_{4}$ & 0.9750 & 0.0640 & 8.1982 & 0.7136 & 0.2019 & 183.4232 \\
HCRI $_{1}$ & 0.9943 & 0.0306 & 1.8762 & $\mathbf{0 . 7 9 7 6}$ & $\mathbf{0 . 1 7 4 0}$ & $\mathbf{5 4 . 4 8 6 8}$ \\
HCRI $_{2}$ & $\mathbf{0 . 9 9 8 8}$ & $\mathbf{0 . 0 1 4 0}$ & $\mathbf{0 . 4 1 2 6}$ & 0.7582 & 0.1881 & 63.6719 \\
Center & 0.3891 & 0.2658 & 317.5832 & 0.2799 & 0.2772 & 345.4699 \\
Depth & 0.9659 & 0.0746 & 11.1394 & 0.6883 & 0.2092 & 78.7987 \\
Area & 0.9716 & 0.0682 & 7.5767 & 0.6413 & 0.2213 & 88.1608 \\
Asymmetry & -0.0027 & 0.2984 & 373.9998 & -0.0043 & 0.2888 & 374.8217 \\
\hline
\end{tabular}

\section{Discussion}

\subsection{The Absorption Feature in the Four Major Surface Constituents Spectra}

The spectra of exposed bedrocks in karst areas have an obvious absorption feature near $2.340 \mu \mathrm{m}$ (see Figure 6a), but the absorption features parameters including absorption endpoints, center wavelength position, depth, area and asymmetry vary with the different bedrock samples (see Table 3). Occurrence of prominent absorption feature in the SWIR spectra around 2.3-2.35 $\mu \mathrm{m}$ due to the vibrational processes of carbonate ions $\left(\mathrm{CO}_{3}^{2-}\right)$ can be used to distinguish carbonate mineral mixtures in the rock samples $[25,39,50]$. According to these previous studies, the slight shifts exhibiting in the wavelength position might indicate that the slight change of ratio of calcite and dolomite in the samples, and the observed rock is likely a limestone suffering local dolomitization processes by replacement of $\mathrm{Ca}$ by $\mathrm{Mg}$ in carbonate (from $\mathrm{CaCO}_{3}$ to $\mathrm{CaMg}\left(\mathrm{CO}_{3}\right)_{2}$ ). Meanwhile, the absorption depth and area depend on the carbonate mineral concentrations, even though the absorption features of the SWIR carbonate spectra may be affected subtly by varying grain sizes [25,51], weathering, and mixing with organic matters forming a coating on carbonate particles $[22,23,26]$ in the rock samples.

The spectra of soils in karst areas exhibit common absorption about a central wavelength near $2.203 \mu \mathrm{m}$ (see Figure $6 \mathrm{~b}$ and Table 2), which indicates that the soils contain clay minerals, and the clay content may determine the absorption depth and area according to [32,48]. As displayed in Figure $6 c$, the green vegetation has no significant spectral absorption in $2.149-2.398 \mu \mathrm{m}$. In contrast, NPV reflectance represents strong absorption signals of lingnin and cellulose near $2.100 \mu \mathrm{m}$ and $2.300 \mu \mathrm{m}[52,53]$. Thus, in SWIR 2.0-2.5 $\mu \mathrm{m}$, there are obvious differences in the reflectance spectra not only between carbonate rocks and the other three constituents, but also among the other three 
constituents. The contribution to spectral absorption in 2.149-2.398 $\mu \mathrm{m}$ is not only from carbonate rocks but also may come from soils. Nevertheless, it may have several problems in the identification of carbonate rock spectra. This may be due to the limitations of spectral resolution as compared to the field spectra. The position of absorption band of these surface constituents may be at significantly different wavelengths, and these spectral absorption may be weakly detected and characterized by the lower spectral resolution spectroscopy instruments.

\subsection{Estimating Carbonate Rock Fraction Using Synthetic Reflectance Spectra}

The distinct positions of the absorption feature in mixed spectra in $2.300-2.350 \mu \mathrm{m}$, comparing to the absorptions of carbonate rocks, green vegetation, soils, and NPV, suggests that the detection and fraction quantification of carbonate rocks by reflectance spectra could be practicable. The unique absorption feature has been described to be a strong underpinning for spectral-index model that utilizes spectra to quantify karst surface land cover fractions. Yue et al. represented carbonate rocks absorption features in 2.200-2.380 $\mu \mathrm{m}$ compared with the soils and NPV absorption features, they defined KRDSIs with the fixed parameters: $\lambda_{a}=2.200 \mu \mathrm{m}, \lambda_{b}=2.380 \mu \mathrm{m}$ and $\lambda_{c}=2.350 \mu \mathrm{m}$ in [20], in order to predict carbonate rock fractions of surface constituents mixtures. These focus on specific wavelengths where the biochemical and geochemistry of interest has its greatest effect. However, in the spectra of mixtures near $2.340 \mu \mathrm{m}$, the spectral absorption is not only affected by carbonate rocks, but by the other surface constituents. The overlapping absorptions make it more complicated to estimate carbonate rocks uniquely.

The spectra of carbonate rocks have a stronger absorption feature from 2.149 to $2.398 \mu \mathrm{m}$ (see Figure 6a and Table 2), Meanwhile, another absorption feature have been observed in the spectra of soils in 2.133-2.304 caused by clay, which induced the jump of position of absorption from 2.340 to $2.203 \mu \mathrm{m}$ with the decrease of carbonate rock fraction in mixed spectra. For these reasons, we focused on the $2.340 \mu \mathrm{m}$ feature, developed two indices with the adjusted KRDSIs parameters and directly related them to carbonate rock fractions using synthetic mixture samples linear regression (see Table 4 and Figure 7).

In the experiment of data set 2 , strong relationships were found with feature depth and area, KRDSIs and HCRIs using the adjusted absorption parameters $(r>0.95$ and RMSE $<0.08)$. Comparatively, the HCRIs had better performance than the KRDSIs, especial for the mixtures with low carbonate rock fractions (see Figure 7). Possible reasons for the lower $r$ and higher RMSE should be that the impact of clay in soils and the induced variant absorption of synthetic mixed spectra in 2.149-2.398 $\mu \mathrm{m}$ region. Similar results were found in the experiment of data set 3 , which make clear that the proposed absorption features in 2.270-2.398 $\mu \mathrm{m}$ region could do better than the features in 2.200-2.38 $\mu \mathrm{m}$ region in estimating carbonate rock fraction. Comparing with the experiment results of data set 2 , data set 3 had obvious lower $r$ and higher RMSE value, the likely cause of which is the different carbonate mineral concentrations in the rocks samples. Moreover, better performance of $\mathrm{HCRI}_{2}$ than $\mathrm{HCRI}_{1}$ was found in the experiment of data set ${ }_{2}$, and a contrary result was found in the experiment of data set 3 , which might indicate that the $\mathrm{HCRI}_{2}$ do better than $\mathrm{HCRI}_{1}$ in characterizing the spectral absorption near $2.340 \mu \mathrm{m}$. However, the absorption not only depends on carbonate rock fraction but also on carbonate mineral concentrations in rocks, and $\mathrm{HCRI}_{1}$ may be a good compromise in dealing with more subtle spectral influences due to carbonate mineralogy, the components and physical state of rock surface $[22,25,26]$. (see Table $4, r=0.7976$, RMSE $=0.1740$ and $\chi^{2}=54.4868$ ). Future studies should focus on this issue. 

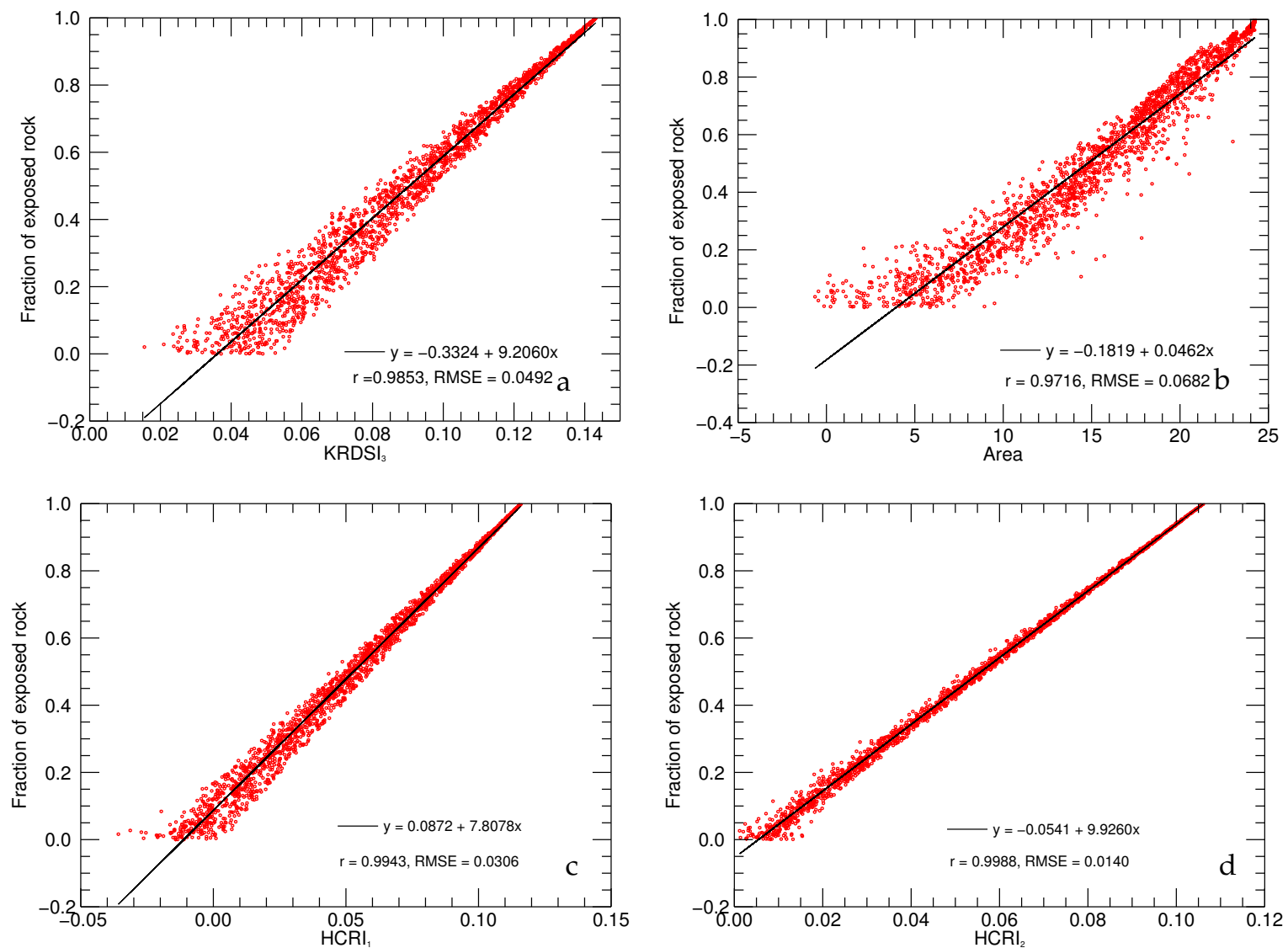

Figure 7. Linear regression results for $2.340 \mu \mathrm{m}$ absorption features of the second synthetic karst surface mixtures and carbonate rock fraction: (a) feature $\mathrm{KRDSI}_{3}$; (b) feature absorption area; (c) feature $\mathrm{HCRI}_{1} ;(\mathbf{d})$ and feature HCRI 2 .

\subsection{Potential of Estimating Carbonate Rock Fraction Using Remote Sensing Imagery}

Field spectroscopy provides an understanding of the interrelationships between the spectral characteristics of objects and their biophysical attributes in the field environment, and a tool for the development, refinement and testing of models relating biophysical attributes to remotely-sensed data [54]. Therefore, it has been used for the development of quantitative models for estimation of carbonate rock fraction in karst mixed surface scenes. On the one hand, the proposed HCRIs provide a potential method for fractional cover mapping of carbonate rocks using aerial or satellite imagery with the sensitive bands in $2.0-2.5 \mu \mathrm{m}$. On the other hand, several factors, including the spectral interval of the SWIR band and the degree of isotropy of the surface being sensed, complicate the estimation of surface fractional cover from remotely sensed imagery [55-57]. Firstly, the three absorption parameters $\lambda_{1}, \lambda_{2}$ and $\lambda_{0}$ in HCRIs should be adjusted according to the spectral resolution of different related sensors from the ASD spectrometer. Secondly, because of the linear mixture assumption, a three-dimensional structure, such as that induced by vegetation vertical heterogeneity, is unconsidered. However, in three-dimensional mixed scenes, the prevalence of multiple scattering can make the mixture of constituents become more complex and non-linear [57]. In rugged karst terrain, the geometry between the sun, the surface orientation, and the satellite sensor, which can vary from one pixel to another, is an additional factor which makes the estimation of surface fractional cover from remotely sensed data difficult [56]. Therefore, these factors should be considered in the application of aerial or satellite remote sensing to estimation of carbonate rock fraction in karst terrain. 


\section{Conclusions}

Different absorption features in 2.0-2.5 $\mu \mathrm{m}$ were detected in the spectra of exposed bedrocks, soils, green vegetation and non-photosynthetic vegetation (NPV) in karst rocky desertification areas. The exposed bedrocks had an obvious absorption feature near $2.340 \mu \mathrm{m}$, but soils consisting of clay minerals had an absorption centered at $2.203 \mu \mathrm{m}$. Absorption signals near $2.100 \mu \mathrm{m}$ and $2.300 \mu \mathrm{m}$ were shown in NPV reflectance and a weak absorption in 2.220-2.400 $\mu \mathrm{m}$. These overlapping absorptions by the other surface constituents were observed to cause complicating of the absorption feature near $2.340 \mu \mathrm{m}$ in synthetic mixed spectra. The complexity was evidenced by varying absorption feature endpoints, centers, depths and areas computed using continuum removal and spectral feature analysis methods. After the spectral feature analysis, we found that the contribution to spectral absorption in 2.149-2.398 $\mu \mathrm{m}$ was not only from carbonate rocks but also from soils. The reflectance spectra of karst surface constituents were of different shapes in the $2.149-2.340 \mu \mathrm{m}$ region; in contrast, the spectra of other surface constituents had slowly changing and similar shapes in the $2.340-2.398 \mu \mathrm{m}$ region.

Based on the founding of the impact of clay in soils on the absorption features of exposed carbonate bedrocks, the parameters $\lambda_{a}, \lambda_{b}$ and $\lambda_{c}$ in karst rocky desertification synthesis indices (KRDSIs) were redefined and two indices (named HCRIs) were developed with them to distinguish the spectral impacts of carbonate rocks on the $2.340 \mu \mathrm{m}$ absorption feature. Compared to the absorption features including depths, areas, and KRDSIs, linear regression of HCRIs with carbonate rock fraction in linear synthetic mixtures resulted in higher correlations and lower errors. In addition, a simple difference index $\left(\mathrm{HCRI}_{1}\right)$ derived directly from the two parameters $\lambda_{2}$ and $\lambda_{0}$ had better performance in bedrock fraction estimating with different carbonate rock samples. Still, new detailed studies are required to advance our knowledge of the spectral influences of carbonate rocks of various types relative to carbonate mineralogy, the components and physical state of rock surface. Several factors, including the spectral resolution of sensors, vegetation vertical heterogeneity and topography, should be considered in terrestrial remote sensing applications in estimation of carbonate rock fraction in karst terrain.

Acknowledgments: This work is supported by the Project of China Geological Survey under Grant No. 12120113007500, the Priority Academic Program Development of Jiangsu Higher Education Institution (PAPD), and the Fundamental Research Funds for the Central Universities. The authors thank Professor Changqing Ke for providing the ASD FieldSpec 4 spectrometer. The authors would like to thank Erzhu Li and Meiqin Che, who kindly supported and facilitated of the spectral measurements at Jiangsu Provincial Key Laboratory of Geographic Information Science and Technology, Nanjing University, China.

Author Contributions: Xiangjian Xie conceived, designed, and performed the experiments under the supervision of Shufang Tian and Peijun Du, who are also the PIs of the project. Peijun Du, Wenfeng Zhan and Shufang Tian designed the data analytic methods. Xie wrote the paper with assistance from Du, Zhan and Tian.Alim Samat and Jike Chen helped with discussion and revisions

Conflicts of Interest: The authors declare no conflict of interest.

\section{References}

1. Van Beynen, P.E. Karst Management; Springer Science \& Business Media: Dordrecht, The Netherlands, 2011.

2. Brinkmann, R.; Parise, M. Karst environments: Problems, management, human impacts, and sustainability an introduction to the special issue. J. Cave Karst Stud. 2012, 74, 135-136.

3. Yuan, D. Modern karstology and global change study. Earth Sci. Front. 1997, 4, 21-29. (In Chinese with English Abstract)

4. Wang, S.; Liu, Q.; Zhang, D. Karst rocky desertification in southwestern China: Geomorphology, landuse, impact and rehabilitation. Land Degrad. Dev. 2004, 15, 115-121.

5. Guo, F.; Jiang, G.; Yuan, D.; Polk, J.S. Evolution of major environmental geological problems in karst areas of Southwestern China. Environ. Earth Sci. 2013, 69, 2427-2435.

6. Wu, H.; Chen, S.; Li, J. Remote sensing analysis and prognosis of desertification in Du'An. Remote Sens. Land Resour. 2002, 14, 15-19. (In Chinese with English Abstract) 
7. Li, W.; Yu, D. A study of the technology for remote sensing investigation of rocky desertification in areas of karst stony hills. Remote Sens. Land Resour. 2002, 14, 34-37. (In Chinese with English Abstract)

8. Hu, J.; An, Y.; Zhou, X. CBERS-supported special information selection method in karst mountain-A case study in Duyun City, Guizhou. Carsologica Sinca 2006, 25, 313-319. (In Chinese with English Abstract)

9. Huang, Q.; Cai, Y. Mapping Karst Rock in Southwest China. Mt. Res. Dev. 2009, 29, 14-20.

10. Qu, L.; Han, W.; Lin, H.; Zhu, Y.; Zhang, L. Estimating Vegetation Fraction Using Hyperspectral Pixel Unmixing Method: A Case Study of a Karst Area in China. IEEE J. Sel. Top. Appl. Earth Obs. Remote Sens. 2014, 7, 4559-4565.

11. Zhang, X.; Shang, K.; Cen, Y.; Shuai, T.; Sun, Y. Estimating ecological indicators of karst rocky desertification by linear spectral unmixing method. Int. J. Appl. Earth Obs. Geoinf. 2014, 31, 86-94.

12. Powell, R.L.; Roberts, D.A.; Dennison, P.E.; Hess, L.L. Sub-pixel mapping of urban land cover using multiple endmember spectral mixture analysis: Manaus, Brazil. Remote Sens. Environ. 2007, 106, 253-267.

13. Franke, J.; Roberts, D.A.; Halligan, K.; Menz, G. Hierarchical Multiple Endmember Spectral Mixture Analysis (MESMA) of hyperspectral imagery for urban environments. Remote Sens. Environ. 2009, 113, 1712-1723.

14. Li, L.; Tong, L.; Li, X. The remote sensing karst rocky desertification extraction method based on vegetation coverage. Remote Sens. Land Resour. 2010, 22, 59-62. (In Chinese with English Abstract)

15. Zhang, P.; Hu, Y.; Xiao, D.; Li, X.; Yin, J. A Method of the Percentage of Bare Rock Calculation in Karst Areas Based on Multi-spectrum Remote Sensing Image. Remote Sens. Tech. Appl. 2010, 20, 510-514. (In Chinese with English Abstract)

16. Xia, X.; Tian, Q.; Du, F. Retrieval of rock-desertification degree from multi-spectral remote sensing images. J. Remote Sens. 2006, 10, 469-474. (In Chinese with English Abstract)

17. Tong, L. A method for extracting remote sensing information from rocky desertification areas in southwest china. Remote Sens. Land Resour. 2003, 4, 35-38. (In Chinese with English Abstract)

18. Xie, X.; Du, P.; Xia, J.; Luo, J. Spectral Indices for Estimating Exposed Carbonate Rock Fraction in Karst Areas of Southwest China. IEEE Geosci. Remote Sens. Lett. 2015, 12, 1988-1992.

19. Green, R.O.; Eastwood, M.L.; Sarture, C.M.; Chrien, T.G.; Aronsson, M.; Chippendale, B.J.; Faust, J.A.; Pavri, B.E.; Chovit, C.J.; Solis, M.; et al. Imaging spectroscopy and the airborne visible/infrared imaging spectrometer (AVIRIS). Remote Sens. Environ. 1998, 65, 227-248.

20. Yue, Y.; Zhang, B.; Wang, K.; Liu, B.; Li, R.; Jiao, Q.; Yang, Q.; Zhang, M. Spectral indices for estimating ecological indicators of karst rocky desertification. Int. J. Remote Sens. 2010, 31, 2115-2122.

21. Yue, Y.M.; Wang, K.L.; Liu, B.; Li, R.; Zhang, B.; Chen, H.S.; Zhang, M.Y. Development of new remote sensing methods for mapping green vegetation and exposed bedrock fractions within heterogeneous landscapes. Int. J. Remote Sens. 2013, 34, 5136-5153.

22. Hunt, G.R.; Salisbury, J.W. Visible and near infrared spectra of minerals and rocks. II. Carbonates. Mod. Geol. 1971, 2, 23-30.

23. Van der Meer, F. Spectral reflectance of carbonate mineral mixtures and bidirectional reflectance theory: Quantitative analysis techniques for application in remote sensing. Remote Sens. Rev. 1995, 13, 67-94.

24. Gaffey, S.J. Reflectance spectroscopy in the visible and near-infrared (0.35-2.55 $\mu \mathrm{m})$ : Applications in carbonate petrology. Geology 1985, 13, 270-273.

25. Gaffey, S.J. Spectral reflectance of carbonate minerals in the visible and near infrared (0.35-2.55 microns): Calcite, aragonite, and dolomite. Am. Mineral. 1986, 71, 151-162.

26. Crowley, J.K. Visible and near-infrared spectra of carbonate rocks: Reflectance variations related to petrographic texture and impurities. J. Geophys. Res. 1986, 91, 5001-5012.

27. Adams, J.B.; Smith, M.O.; Johnson, P.E. Spectral mixture modeling: A new analysis of rock and soil types at the Viking Lander 1 site. J. Geophys. Res. Solid Earth 1986, 91, 8098-8112.

28. Kokaly, R.F.; Despain, D.G.; Clark, R.N.; Livo, K.E. Mapping vegetation in Yellowstone National Park using spectral feature analysis of AVIRIS data. Remote Sens. Environ. 2003, 84, 437-456.

29. Urich, P.B. Land Use in Karst Terrain: Review of Impacts of Primary Activities on Temperate Karst Ecosystems; Department of Conservation: Wellington, New Zealand, 2002.

30. Kokaly, R.F.; Skidmore, A.K. Plant phenolics and absorption features in vegetation reflectance spectra near $1.66 \mu \mathrm{m}$. Int. J. Appl. Earth Obs. Geoinf. 2015, 43, 1-29.

31. Settle, J.J.; Drake, N.A. Linear mixing and the estimation of ground cover proportions. Int. J. Remote Sens. 1993, 14, 1159-1177. 
32. Clark, R.; Roush, T. Reflectance Spectroscopy: Quantitative Analysis Techniques for Remote Sensing Applications. J. Geophys. Res. 1984, 89, 6329-6340.

33. Clark, R.N.; King, T.V.V.; Gorelick, N.S. Automatic continuum analysis of reflectance spectra. In Proceedings of the Third AIS workshop, Pasadena, CA, USA, 2-4 June 1987; pp. 138-142.

34. Green, A.A.; Craig, M.D. Analysis of aircraft spectrometer data with logarithmic residuals. In Proceedings of the Third AIS workshop,Pasadena, CA, USA, 8-10 April 1985; pp. 111-129.

35. Kruse, F.A.; Raines, G.L.; Watson, K. Analytical techniques for extracting geologic information from multichannel airborne spectroradiometer and airborne imaging spectrometer data. In Proceedings of the 4th International Symposium on Remote Sensing of Environment, Thematic Conference on Remote Sensing for Exploration Geology, San Francisco, CA, USA, 1-4 April 1985; pp. 309-324.

36. Kruse, F.; Lefkoff, A.; Dietz, J. Expert system-based mineral mapping in northern Death Valley, California/Nevada, using the airborne visible/infrared imaging spectrometer (AVIRIS). Remote Sens. Environ. 1993, 44, 309-336.

37. Kruse, F.; Lefkoff, A. Knowledge-based geologic mapping with imaging spectrometers. Remote Sens. Rev. 1994, 8, 3-28.

38. Kokaly, R.F.; Clark, R.N. Spectroscopic determination of leaf biochemistry using band-depth analysis of absorption features and stepwise multiple linear regression. Remote Sens. Environ. 1999, 67, 267-287.

39. Clark, R.N.; Swayze, G.A.; Livo, K.E.; Kokaly, R.F.; Sutley, S.J.; Dalton, J.B.; McDougal, R.R.; Gent, C.A. Imaging spectroscopy: Earth and planetary remote sensing with the USGS Tetracorder and expert systems. J. Geophys. Res. Planets 2003, 108, 5131-5146.

40. Van der Meer, F. Analysis of spectral absorption features in hyperspectral imagery. Int. J. Appl. Earth Obs. Geoinf. 2004, 5, 55-68.

41. Kokaly, R.F.; Asner, G.P.; Ollinger, S.V.; Martin, M.E.; Wessman, C.A. Characterizing canopy biochemistry from imaging spectroscopy and its application to ecosystem studies. Remote Sens. Environ. 2009, 113, S78-S91.

42. Kokaly, R.F. PRISM: Processing Routines in IDL for Spectroscopic Measurements (Installation Manual and User's Guide, Version 1.0); Technical Report; US Geological Survey: Reston, VA, USA, 2011.

43. Carlson, T.N.; Ripley, D.A. On the relation between NDVI, fractional vegetation cover, and leaf area index. Remote Sens. Environ. 1997, 62, 241-252.

44. Nagler, P.L.; Inoue, Y.; Glenn, E.P.; Russ, A.L.; Daughtry, C.S.T. Cellulose absorption index (CAI) to quantify mixed soil-plant litter scenes. Remote Sens. Environ. 2003, 87, 310-325.

45. Ninomiya, Y. A stabilized vegetation index and several mineralogic indices defined for ASTER VNIR and SWIR data. In Proceedings of the 2003 IEEE International Geoscience and Remote Sensing Symposium, Toulouse, France, 21-25 July 2003; Volume 3, pp. 1552-1554.

46. Deng, C.; Wu, C. BCI: A biophysical composition index for remote sensing of urban environments. Remote Sens. Environ. 2012, 127, 247-259.

47. Brown, D.J. Using a global VNIR soil-spectral library for local soil characterization and landscape modeling in a 2nd-order Uganda watershed. Geoderma 2007, 140, 444-453.

48. Stenberg, B.; Rossel, R.A.V.; Mouazen, A.M.; Wetterlind, J. Visible and near infrared spectroscopy in soil science. In Advances in Agronomy; Sparks, D.L., Ed.; Academic Press: Burlington, ON, Canada, 2010; Volume 107, pp. 163-215.

49. Johnson, P.E.; Smith, M.O.; Taylor-George, S.; Adams, J.B. A semiempirical method for analysis of the reflectance spectra of binary mineral mixtures. J. Geophys. Res. Solid Earth 1983, 88, 3557-3561.

50. Zaini, N.; van der Meer, F.; van der Werff, H. Determination of carbonate rock chemistry using laboratory-based hyperspectral imagery. Remote Sens. 2014, 6, 4149-4172.

51. Zaini, N.; van der Meer, F.; van der Werff, H. Effect of grain size and mineral mixing on carbonate absorption features in the SWIR and TIR wavelength regions. Remote Sens. 2012, 4, 987-1003.

52. Daughtry, C.S.T. Agroclimatology: Discriminating crop residues from soil by shortwave infrared reflectance. Agron. J. 2001, 93, 125-131.

53. Thenkabail, P.S.; Lyon, J.G.; Huete, A. Hyperspectral Remote Sensing of Vegetation; CRC Press: Boca Raton, FL, USA, 2011.

54. Milton, E.J. Review Article Principles of field spectroscopy. Int. J. Remote Sens. 1987, 8, 1807-1827.

55. Brest, C.L.; Goward, S.N. Deriving surface albedo measurements from narrow band satellite data. Int. J. Remote Sens. 1987, 8, 351-367. 
56. Proy, C.; Tanre, D.; Deschamps, P. Evaluation of topographic effects in remotely sensed data. Remote Sens. Environ. 1989, 30, 21-32.

57. Hu, B.; Lucht, W.; Li, X.; Strahler, A.H. Validation of kernel-driven semiempirical models for the surface bidirectional reflectance distribution function of land surfaces. Remote Sens. Environ. 1997, 62, 201-214.

(C) 2016 by the authors; licensee MDPI, Basel, Switzerland. This article is an open access article distributed under the terms and conditions of the Creative Commons by Attribution (CC-BY) license (http:/ / creativecommons.org/licenses/by/4.0/). 